\title{
A treatment approach of mandibular implant retained overdenture: A case report
}

\author{
Ijaz Ahmad Bhat ${ }^{*}$, Archna Nagpal ${ }^{2}$, Alka Chaoudhary $^{3}$, Komal $^{4}$, Harvinder Singh Gill $^{5}$ \\ 1,3-5 Post Graduate Student, ${ }^{2}$ Professor and HOD, ${ }^{1-5}$ Dept. of Prosthodontics Crown \& Bridge, Himachal Dental College, \\ Sundar Nagar, Mandi, Himachal Pradesh, India \\ *Corresponding Author: Ijaz Ahmad Bhat \\ Email: drijazbhat11@gmail.com
}

\begin{abstract}
Edentulism has been a big issue whether it is in old age or in young individuals. The geriatric patients often encounter problems because of the absorbed mandibular ridges. The most common problem faced is the lack of stability and retention of the mandibular denture which ultimately affect the chewing and masticatory efficacy of the patients. Since ages the conventional complete denture is used as a treatment modality for edentulous patients but in last 20 years the implant supported overdenture has emerged as new option for edentulous patients. The use of implant supported overdenture had increased over a time because of good clinical results. The clinical edge of implant supported overdenture over conventional denture is that it can be given in resorbed ridges. The prosthesis shows less movement, better esthetics, improved function and maintenance of vertical dimension of occlusion over time. The higher success is associated with the implant supported overdenture because it meets the patients' expectations, improve quality of life with long term serviceability and positive outcomes.
\end{abstract}

Keywords: Implant, Over-denture, O-ring, Edentulous mandible.

\section{Introduction}

The concept of using dental implants to replace teeth is an age old technique. Since ancient history times thousands of years ago, ivory teeth were used as implants in Egyptian mummies. However, the era of modern dental implantology began much later, in the 1940 's, with the discovery of screw type implants by Formiggini et al. ${ }^{1,2}$ Dental implants are prosthetic devices, made of alloplastic materials that are inserted into the oral cavity to provide retention and support to removable and fixed dental prostheses. ${ }^{3,4}$ Another milestone in the history of dental implantology was the introduction of the concept and the biology of osseointegration, by Brånemark et al. ${ }^{5}$ The extensively used treatment modality for oral rehabilitation which has emerged over the years is implantology. ${ }^{6}$ The dentist and the patient experience great transformation while possessing edentulous state and great challenges for the clinicians while dealing with the same. Implant born prosthesis whip hand conventional prosthesis and can be considered as effective alternative because it offers various advantages such as preservation of bone volume, improve retention, stability, function and comfort. $^{7}$ As the successful use of dental implants in the treatment of mandibular edentulism is welldocumented in the literature ${ }^{8}$ for both fixed and removable prosthetic rehabilitations, ${ }^{9}$ these problems can be easily solved by using implant retained prosthesis (IRP)/implant supported prosthesis (ISP). IRP achieves support from both implants and tissues whereas ISP achieves support only from implants. ${ }^{10}$ The placement of implants in the resorbed residual ridges provide favourable environment for restoration. Implant supported fixed prosthesis offer more advantages like it is aesthetically pleasant and look alike natural dentition but do have disadvantages too such as it is not economically pleasant and it is not clinically indicated in many conditions. ${ }^{12}$ Implant supported removable prosthesis have more advantages than fixed prosthesis in a way that they require less chair time and less financial expenses. ${ }^{13}$

The implant supported overdenture is economical treatment option as it provide facial support, easy to construct, can restore both dental and alveolar tissues. Various designs are available for the implant supported overdenture based upon the attachment 
system which can be stud, magnet and bar which eventually depends upon the number of implants, patient expectations, retention required and cost. ${ }^{16}$

\section{Case Report}

A 67 year old male reported to the Department of Prosthodontics, Himachal Dental College and Hospital, Sundernagar, Mandi, India, with the chief complaint of loose-fitting of mandibular denture. Patient had been completely edentulous in mandibular arch and partially edentulous in maxillary arch since last 1.5 years. Patient had been using mandibular complete denture and maxillary removable partial denture for past 6 months and was not satisfied with lower denture due to lack of retention and difficulty in chewing food. On clinical examination ridge relation was class I and Mandibular ridge resorption was Atwoods class IV. There were many treatment options available and most appropriate treatment option to rehabilitate the patient was mandibular implantsupported overdenture opposing maxillary removable partial denture.

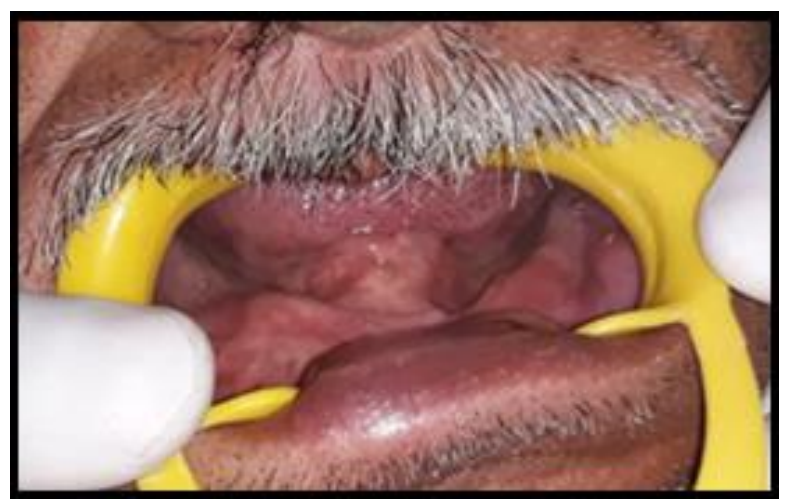

Fig. 1: Pre op

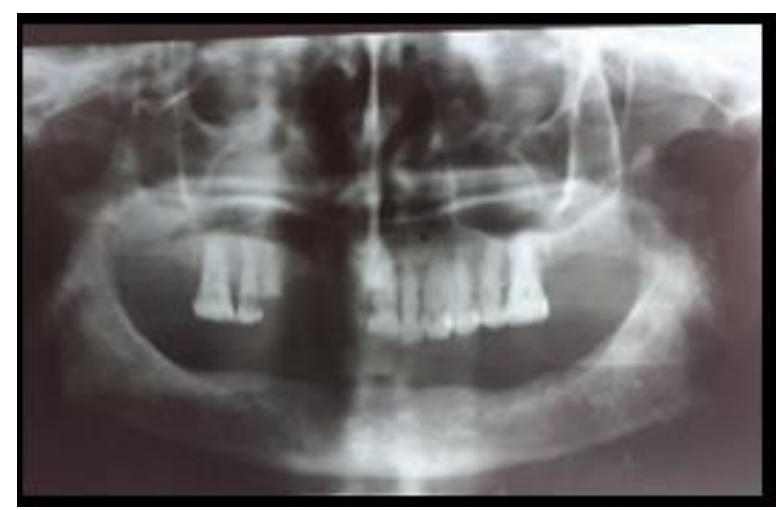

Fig. 2: Pre op OPG

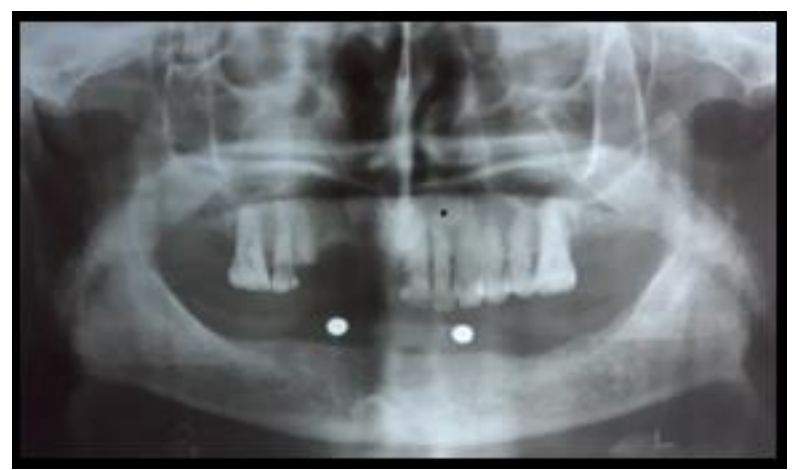

Fig. 3: Position B and D

Orthopantomogram (OPG), diagnostic casts and records were studied. According to the Misch's overdenture criteria - OD $1{ }^{12}$ two Implant were planned at $\mathrm{B}$ and D positions. (Fig. 1-3)The whole treatment was divided into three parts: (1) mandibular denture fabrication, (2) implant placement (surgery), and (3) $2^{\text {nd }}$ stage (prosthesis engagement after three months).

\section{Denture and RPD fabrication}

Mandibular complete denture and maxillary RPD was fabricated using conventional steps for denture fabrication. Fabrication of mandibular denture and maxillary RPD was useful for interarch space analysis (Fig. 4-5)



Fig. 4: master impression 




Fig. 5: try-in

\section{Implant placement}

Two (bio-line) implants of $3.75 \times 11 . \mathrm{mm}^{5}$ were selected at B and D positions. Attachment system used for this case was Ball and socket type. Under local anesthesia implant placement was performed. The osteotomy at B and D region of mandibular arch was prepared. Parallelism was checked using guide pin between the implants. The selected implants were placed after osteotomy of the $\mathrm{B} \& \mathrm{D}$ region. Cover screws were placed and flaps were closed with sutures (Nylon 4-0). (Fig. 6-8)

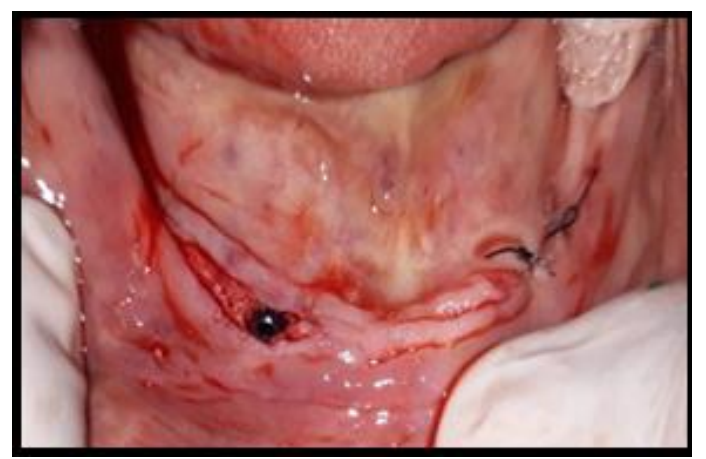

Fig.6: Implant placement

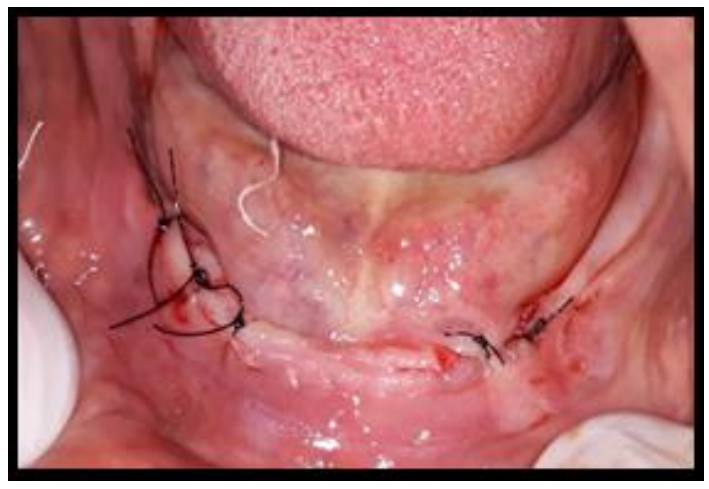

Fig.7: Flap closure



Fig. 8: Post op OPG

After implant surgery, patient was instructed not to wear the mandibular denture for 10-15 days. Patient was put on antibiotics for 7 days.To maintain oral hygiene patient was told use disinfectant mouth was 35 times daily(Listerine). Patient was told to have soft and liquid diet. After one week patient was recalled and sutures were removed. To avoid selective pressure over implant site and to help osseointegration of implants the tissue surface of the mandibular denture was relieved.Tissue conditioner (GC Reline Soft TM) was applied to act as cushion between the occlusal force and tissue base. After trimming, finishing and polishing of the denture was done, prosthesis was inserted into the patients mouth (Fig 9-10).

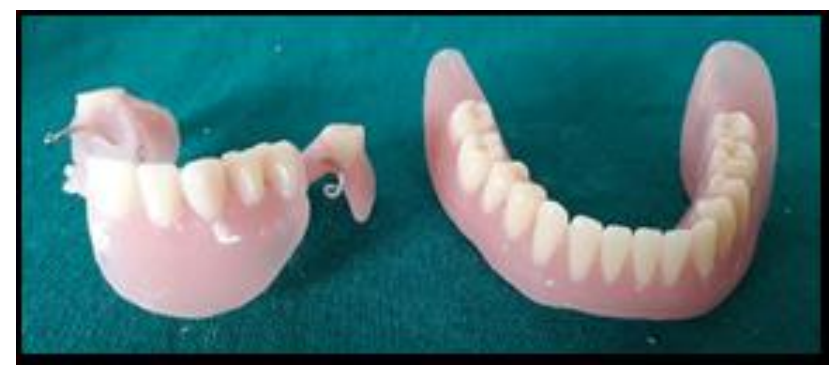

Fig. 9: Finished prosthesis

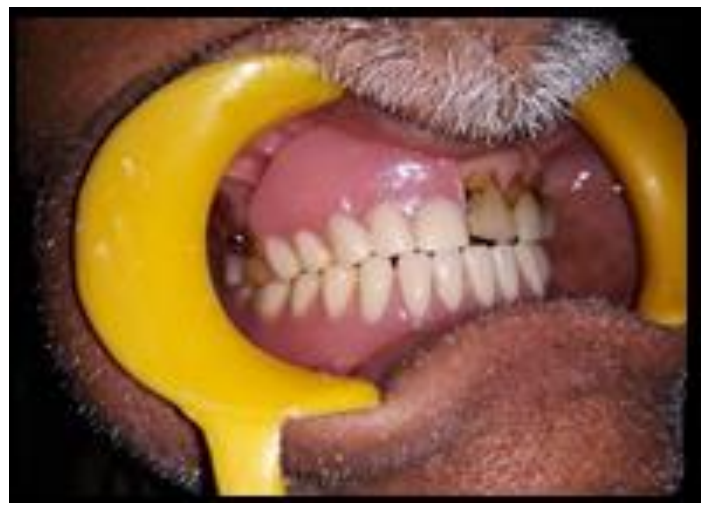

Fig. 10: Insertion of prosthesis 
Post-operative instructions were given to the patient, to maintain hygiene of the prosthesis patient was instructed to use soft tufted brush. Patient was recalled after $24 \mathrm{hrs}$. for denture stability and occlusion corrections.

\section{2nd stage (prosthesis pick up after three months)}

After three months, implant sites B \& D position were exposed, cover screws were removed. Normal saline was used to flush the implant sites. At this stage healing collars were placed, and tissue around the implants sites was left undisturbed to mature for one month. Before proceeding with pick up of denture with attachments, denture stability, fit and comfort was checked. $2 \mathrm{~mm}$ diameter of ball and socket type of over denture attachment was used. (Fig.11-12)



Fig. 11: Attachment abutments



Fig. 12: metal housing and silicone rings

Firstly the seating of the abutments was checked. Interfering contacts of denture and attachment was verified by using pressure indicating paste (PIP). A round bur of no.6 was used to make the space for abutment attachment. After that patient was instructed to close mouth with normal occlusal pressure, while resin polymerise in the pick up space. The extra resin in the pick up space was trimmed and polished and final prosthesis of mandibular implant supported over denture and maxillary flexible RPD was inserted. (Fig. 13-15)

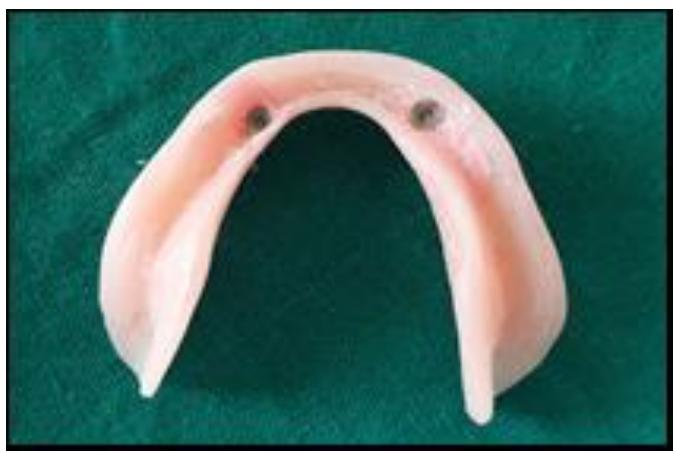

Fig. 13: Pic up denture



Fig. 14: Flexible RPD

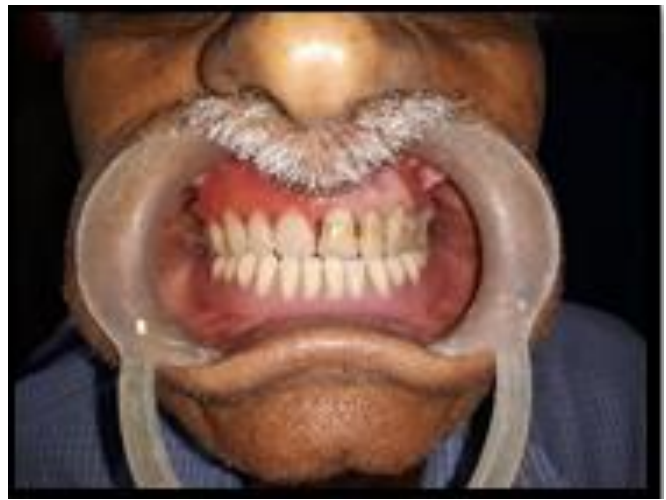

Fig. 15: Final prosthesis

\section{Discussion}

One of the main advantage of the mandibular implant supported over denture is the retention during the mandibular movements and functioning of the tongue. There are two ways of approaches to design the over- 
dentutre. ${ }^{17}$ In the first design approach, implants are splinted with a rigid interconnecting bar on which attachment system are incorporated to enhance retention. In second design approach, implants are not connected to each other, but the retention system is provided by the attachments. Free standing implants has got the advantage of using prefabricated stock retentive abutments. On the other hand, bar system of implant supported over denture require additional laboratory and clinical procedures for the fabrication and also becomes costly for the patient. In case of compromise alignment or position of implants, stock abutments are not used because they don't provide desired results. In case of splinting implants with bar, they compromise these problems. In abutment failure cases, prefabricated abutments has got advantage that they can be easily replaced and no necessary of remaking new over denture. However, in case of overdenture with bar mostly require remaking of new over denture.Most of the complication of the implant supported over dentures are of attachment components. As a fact, whatever be the treatment modality, the success of the over-denture is determined by maintenance, care of prosthesis and position of implant. As compared to the conventional denture implant supported over-denture fabrication is technique sensitive and requires precise treatment planning. ${ }^{18}$

\section{Conclusion}

One of the challenging task for the restoring dentist is to rehabilitate the resorbed edentulous mandibular ridge. There are various treatment options available, but an implant-retained overdenture is a simple and cost effective solution to rehabilitate edentulous mandible. Two implant supported over denture has got widespread acceptance, but still some controversies do exist with regard to the design e.g., mechanics of the overdenture, approximate or ideal attachment system, and the most accurate techniques for the overdenture fabrication. Appropriate design principles should be followed by restoring dentist and dental laboratory technicians e.g., simplicity of over-denture fabrication, easy maintenance and repair of prosthesis and should be economical. For planning of ISP/IRP following objectives should be taken into considerations:
1. Regarding the morphological aspects of the residual ridge optimum location and number of implants should be considered.

2. Favourable distribution for occlusal stresses on the implants and the prosthesis bearing tissues.

3. No discrepancies regarding the design of the overdentures prosthesis, the implant's location and the attachment system.

\section{Source of Funding}

None.

\section{Conflict of Interest}

None.

\section{References}

1. Kibrick M, Munir ZA, Lash H, Fox SS. The development of a materials system for an endosteal tooth implant: I. Critical assessment of previous designs. Oral Implantol 1975;6:172-92.

2. Kibrick M, Munir ZA, Lash H, Fox SS. The development of a materials system for an endosteal tooth implant. II. In vitro and in vivo evaluations of a new composite-material design. J Oral Implantol 1977;7:106-23.

3. Meyer U, Joos U, Mythili J, Stamm T, Hohoff A, Fillies T, et al. Ultrastructural characterization of the implant/bone interface of immediately loaded dental implants. Biomater 2004;25:1959-67.

4. The glossary of prosthodontic terms. J Prosthet Dent 2005;94:10-92.

5. Brånemark PI, Adell R, Breine U, Hansson BO, Lindström J, Ohlsson A et al. Intra-osseous anchorage of dental prostheses. I. Experimental studies. Scand J Plast Reconstr Surg 1969;3:81-100.

6. Muhammad AH, Abdulgani A, Bajali M, Giogrges C. The mandibular two-implant overdenture. J Dent Allied Sci 2014;3:58-62.

7. Luthra R, Sharma A, Kaur P. Implant Supported Overdenture: A Case Report. Periodontol Prosthodont 2016;2:2.

8. Jemt T, Chai J, Harnett J, Heath MR, Hutton JE, Johns RB, et al. A 5-year prospective multicenter follow-up report on overdentures supported by osseointegrated implants. Int $J$ Oral Maxillofac Implants 1996;11:291-8.

9. Sadowsky SJ. The implant-supported prosthesis for the edentulous arch: Design considerations. J Prosthet Dent 1997;78:28-33.

10. Bansal S, Aras MA, Chitre V. Guidelines for treatment planning of mandibular implant overdenture. J Dent Implant 2014;4:86-90.

11. Batenburg RH, Meijer HJ, Raghoebar GM, Vissink A. Treatment concept for mandibular overdentures supported 
by endoosseous implants: a literature review. Int J Oral Maxillofac Implants 1998;13(4):539-45.

12. Misch CE. Contemporary implant dentistry. Implant Dent 1999;8(1):90.

13. Kadam KS, Dange SP, Mahale K, Khalikar SA, Khalikar A. Implant-supported Overdenture. Int J Oral Implantol Clin Res 2017;8(1):22-25.

14. Marco F, Milena F, Gianluca G, Vittoria O. Peri-implant osteogenesis in health and osteoporosis. Micron 2005;36:630-44.

15. Qi MC, Zou SJ, Han LC, Zhou HX, Hu J. Expression of bone-related genes in bone marrow MSCs after cyclic mechanical strain: Implications for distraction osteogenesis. Int J Oral Sci 2009;1:43-50.
16. Luthra R, Sharma A, Kaur P. Implant Supported Overdenture: A Case Report. Periodon Prosthodon 2016:2:2.

17. Dipti Lambade, Implant Supported Mandibular Overdenture. J Clin Diagn Res 2014;8(5):ZD04-ZD06

18. Timmerman R, Stoker GT, Wismeijer D. An eight-year follow-up to a randomized clinical trial of participant satisfaction with three types of mandibular implant-retained overdentures. J Dent Res 2004;83:630-3.

How to cite this article: Bhat IA, Nagpal A, Chaoudhary A, Komal, Gill HS. A treatment approach of mandibular implant retained overdenture: A case report. Ann Prosthodont Restor Dent 2019;5(4):125-30. 